\title{
Risk and outcome of subsequent malignancies after radioactive iodine treatment in differentiated thyroid cancer patients
}

\author{
Xiaoran Mei ${ }^{1 \dagger}$, Xiaoqin $\mathrm{Yao}^{2 \dagger}$, Fang Feng ${ }^{1}$, Weiwei Cheng ${ }^{1 *}$ and Hui Wang ${ }^{1 *}$
}

\begin{abstract}
Background: We identified differentiated thyroid cancer (DTC) survivors from SEER registries and performed Poisson regression to calculate the relative risks (RRs) of subsequent malignancies (SMs) by different sites associated with radioactive iodine (RAI) treatment, and the attributable risk proportion of RAI for developing different SMs.

Results: We identified 4628 of 104,026 DTC patients developing a SM after two years of their DTC diagnosis, with a medium follow-up time of 113 months. The adjusted RRs of developing SM associated with RAI varied from 0.98 (0.58-1.65) for neurologic SMs to $1.37(1.13-1.66)$ for hematologic SMs. The RRs of developing all cancer combined SMs generally increased with age at DTC diagnosis and decreased with the latency time. We estimated that the attributable risk proportion of RAI treatment is only $0.9 \%$ for all cancer combined SMs and $20 \%$ for hematologic SMs, which is the highest among all SMs. The tumor features and mortalities in patients treated with and without RAl are generally comparable.

Conclusion: With the large population based analyses, we concluded that a low percentage of DTC survivors would develop SMs during their follow-up. Although the adjusted RR of SMs development increased slightly in patients receiving RAl, the attributable risk proportion associated with RAI was low, suggesting the absolute number of SMs induced by RAI in DTC survivors would be low. The attributable risk proportion of RAI treatment is the highest in hematological SMs, but when in consideration of its low incidence among all DTC survivors, the absolute number of hematological SMs was low.
\end{abstract}

Keywords: Radioactive iodine, Subsequent malignancies, Differentiated thyroid cancer

\section{Introduction}

Differentiated thyroid cancer (DTC) is the most prevalent endocrine cancer and the incidence of DTC has increased dramatically worldwide in the past few decades $[1,2]$. Generally, DTC patients have a favorable prognosis after appropriate treatment, with the 10-year survival

\footnotetext{
* Correspondence: wcheng37@outlook.com; wanghui@xinhuamed.com.cn

${ }^{+}$Xiaoran Mei and Xiaoqin Yao contributed equally to this work.

${ }^{1}$ Xin Hua Hospital Affiliated to Shanghai Jiao Tong University School of Medicine, Shanghai, China

Full list of author information is available at the end of the article
}

rate estimated to be greater than $90 \%[3,4]$. Given the rising incidence and the good prognosis of DTC, the development of a subsequent malignancy $(\mathrm{SM})$ became an important concern for DTC survivors and also physicians [5-7]. It has been reported that DTC survivors have an $10-30 \%$ higher risk of developing a SM comparing with the general population [5-8]. These greater risks are probably a result of the combination of lifestyle, environment, genetic factors and the medical treatment for DTC. 
Radioactive iodine (RAI) is commonly used in DTC treatment [9]. In a recent multicenter cohort study, there were $57.5 \%$ DTC patients received RAI during the initial treatment of primary tumor, lower than $62-75 \%$ reported by National Thyroid Cancer Treatment Cooperative Group based on patients diagnosed between 1987 to 2001 [10, 11]. Increased number of studies support to reduce unnecessary radioiodine treatment in DTC patients in the last decades $[12,13]$. However, the balance of benefits and risks of RAI treatment in DTC patients are still inconclusive yet. While most studies reported RAI treatment is associated with an increased risk of SMs development in DTC survivors [5-8, 14], there are also some investigations suggesting a minor effect of RAI in inducing SMs $[15,16]$. In addition, analyses basing on all adult cancer survivors have indicated that most SMs are actually developed due to nonradiation factors, such as lifestyle or genetics, and concluded that a small proportion of SMs $(<10 \%)$ might be truly related to radiotherapy $[17,18]$. Among all these studies investigating the risks of SMs in DTC survivors, none of them regarding the attributable risk of RAI treatment in inducing SMs development. Moreover, very few studies compared the biological features of SMs in RAI treated and non-RAI treated DTC survivors, as well as the clinical outcome of the two groups of patients.

Therefore, by using data from the SEER registries, we systemically investigated the proportion of SMs might be induced by RAI treatment in DTC survivors in this study, and also compared the biological features of SMs and the mortality of DTC survivors treated with and without RAI. Our analyses would provide supplemental evidences towards the application of RAI treatment in DTC patients.

\section{Methods}

\section{Data source and participants}

The cohort was assembled using the April 2020 release of all 18 registries of the SEER database which covered approximately $28 \%$ of the US population. As the spectrum of pediatric and adolescent tumor is different from that of adults, only patients aged 20 years or older who were diagnosed with a first primary thyroid cancer of papillary or follicular type between 2000 and 2016 (the histological subtypes included in analysis were ICD codes 8050, 8260, 8290, 8330-8332, 8335, 8340-8344 and 8350 ) were identified by the SEER program statistical analysis software (SEER*Stat, version 8.3.6). We used the variant "summary stage" to define the extent of DTC. As there is a lag time between radiation exposure and SM development, we exclude patients whose followup time were less than 24 months after their diagnosis of thyroid cancer. This criterion also ensured that we minimized the surveillance bias that might generated when patients who received RAI treatment were monitored more intensive than those not in the first 24 months. Our study did not need ethics committee approval because the data are publicly available.

\section{Procedures and statistical analysis}

The SEER*Stat MP-SIR (Multiple Primary-Standardized Incidence Ratio) tool was used to extract the details of all included DTC survivors. We used Poisson regression analysis to estimate the relative risks (RRs) with 95\% CIs and $P$ values of SMs development in DTC survivors who received RAI compared with those who did not. The RRs were estimated for all combined SMs and also for different SMs by their sites, and further adjusted with age at DTC diagnosis, gender, year of DTC diagnosis and tumor stage. The RRs were also estimated in subgroup patients stratified according to their gender, age at DTC diagnosis and latency time from DTC diagnosis to SM diagnosis. The number of excess SMs related to RAI treatment was calculated by taking the number of SMs in those treated with RAI minus the estimated number of SMs in these patients if they were not treated with RAI. Attributable risks were also assessed for different SMs by their sites, which quantify the risk in RAI treated DTC survivors that was attributable to RAI treatment.

The statistical analysis was performed similarly as our previous work [19]. To be specific, categorical data were summarized as frequencies and percentages while continuous data were summarized as medians and interquartile ranges (IQR). The Chi-Squared Test was used to analyze categorical variables while Wilcoxon-MannWhitney test was used to analyze continuous variables. All statistical analyses were performed using SPSS (version 22). Statistical significance was defined as a $P$ value of less than 0.05 , all statistical tests were two sided.

\section{Results}

\section{Patient characteristics}

We identified 104,026 patients with DTC from the SEER database in total, $51,212(49.2 \%)$ patients received RAI as part of their DTC treatment while 52,814(50.8\%) patients did not. Basic demographic and disease characteristics of these DTC patients are shown in Table 1. RAI treated DTC patients tend to have lower percentage of females, younger age, and higher stage of tumors.

During the follow-up period (2000-2016), a total of 4628 (4.4\%) DTC survivors developed SMs. Among them, 2289 patients have received RAI treatment (RAI+) and 2339 patients have not (RAI-), the incidences of all cancer combined SMs in RAI+ and RAI- DTC survivors were $4.5 \%$ versus $4.4 \%$, showing no difference $(P=0.752)$. Breast cancer is the most common SM in all DTC survivors $(1.1 \%)$ while the lowest incidence of SMs are neurologic cancer $(0.06 \%)$ (Table S1). The spectrum of 
Table 1 Characteristics of patients with differentiated thyroid cancer enrolled in this study

\begin{tabular}{|c|c|c|c|}
\hline & + RAI & $-\mathrm{RAI}$ & $P$ value \\
\hline No. of patients, $n$ & 51,212 & 52,814 & \\
\hline Patients with SMs, $\mathrm{n}(\%)$ & $2289(4.5 \%)$ & $2339(4.4 \%)$ & 0.752 \\
\hline Gender & & & $<0.001$ \\
\hline Female & 38,941 & 42,423 & \\
\hline Male & 12,271 & 10,391 & \\
\hline Median age at diagnosis of thyroid cancer (IQR), yrs & $46(36-56)$ & $49(38-59)$ & $<0.001$ \\
\hline Race & & & $<0.001$ \\
\hline White & 41,771 & 42,949 & \\
\hline Black & 2944 & 3983 & \\
\hline Asian and Pacific Islander & 5825 & 4816 & \\
\hline American Indian/Alaska native & 275 & 232 & \\
\hline Unknown & 397 & 834 & \\
\hline Stage* & & & $<0.001$ \\
\hline Localized & $29,943(58.5 \%)$ & $43,872(83.1 \%)$ & \\
\hline Regional & 19,304(37.7\%) & $6987(13.2 \%)$ & \\
\hline Distant & $1650(3.2 \%)$ & $635(1.2 \%)$ & \\
\hline Unknown/unstaged & $315(0.6 \%)$ & $1320(2.5 \%)$ & \\
\hline Median follow-up time (IQR), months & $91(57-133)$ & $85(52-130)$ & $<0.001$ \\
\hline
\end{tabular}

*: Localized: lesions confined to thyroid; Regional: regional by direct extension or/and regional lymph node involved; Distant: distant site(s)/lymph node involved

different SMs was highly overlapped between the two groups (Fig. S1). Exceptions were cancers of digestive and hematologic system, for which SMs of digestive system accounts for a lower percentage $(13.9 \%$ vs $15.2 \%$, $P=0.216)$ and SMs of hematologic system accounts for a higher percentage $(11.4 \%$ vs $9.2 \%, P=0.013)$ in RAI+ group, as compared to RAI- group. The descriptive statistics of different SMs in RAI+ and RAI- patients were listed in Table 2.

\section{Relative risk of developing SMs associated with RAI treatment}

To investigate how much RAI treatment attribute to the increased risk of SMs development, we assessed the crude and adjusted RRs of SMs associated with RAI treatment (Fig. 1 and Table S2). The significant increased RR was only seen for hematologic cancers $(\mathrm{RR}=$ 1.25, 95\%CI: $1.05-1.50 ; P=0.015$ ), and it became more significant after adjusting with age at DTC diagnosis, gender, year of DTC diagnosis and tumor stage $(\mathrm{RR}=$ 1.37, 95\%CI:1.13-1.66; $P=0.001$ ). Adjustment for age at DTC diagnosis, gender, year of DTC diagnosis and DTC tumor stage have a small effect on the RR estimates, generally increasing the risks (Fig. 1 and Table S2). The crude RRs for all cancer combined SMs and breast cancers were 1.01 (95\%CI:0.95-1.07, $P=0.749)$ and 0.98 (95\%CI:0.87-1.11, $P=0.778$ ), and increased to 1.10 (95\%CI:1.03-1.17, $P=0.003)$ and 1.14(95\%CI:1.00-1.29,
$P=0.040)$ respectively after adjustment, which became statistically significant (Fig. 1 and Table S2).

After defining a latency time of two years between DTC diagnosis and SM development, there were an estimated 11 excess SMs for all cancer combined that could be related to RAI treatment in our analysis (Fig. 1). The attributable risk of RAI treatment for SMs development was only $0.9 \%(95 \% \mathrm{CI}:-4.7-6.5 \%)$, indicating RAI treatment only contribute little in inducing SMs development in DTC survivors. This proportion was relatively high in patients developed SMs in hematologic system and oral cavity and pharynx system, for which 20.1 and $11.7 \%$ SMs could be related to RAI treatment, respectively (Fig. 1). This is consistent with other studies reporting RAI is more likely to induce leukemia and salivary gland malignancies $[5,6,16]$.

We additionally assessed effect modification by age, gender and latency time between the diagnosis of DTC and SM. The RRs of SMs development associated with RAI treatment gradually increase with the age at DTC diagnosis, although the significant increase was only seen in patients with their DTC diagnosed between 60 and 74 yrs. $(\mathrm{RR}=1.17,95 \% \mathrm{CI}: 1.05-1.30, P=0.004)($ Table 3$)$. By contrast, the RRs for hematologic SMs were significantly increased in all age subgroups, excepting patients with DTC diagnosed older than 75 yrs. (Table 3). Both genders were not at the increased risk of all cancer combined SMs associated with RAI treatment, but females receiving RAI had an increased risk of hematologic SMs 
Table 2 Descriptive statistics of the SMs in DTC survivors by their treatment

\begin{tabular}{|c|c|c|c|c|c|c|c|c|c|c|c|c|c|c|}
\hline & \multicolumn{2}{|c|}{$\begin{array}{l}\text { Number of } \\
\text { patients, } \\
\mathrm{n}(\%)\end{array}$} & \multicolumn{2}{|c|}{$\begin{array}{l}\text { Number of } \\
\text { Females, } \mathrm{n}(\%)\end{array}$} & \multicolumn{2}{|c|}{$\begin{array}{l}\text { Proportion of patients by } \\
\mathrm{race}(\mathrm{W} / \mathrm{B} / \mathrm{API})\end{array}$} & \multicolumn{2}{|c|}{$\begin{array}{l}\text { Proportion of patients by } \\
\text { disease stage (Local/ } \\
\text { Regional/Distant) }\end{array}$} & \multicolumn{2}{|c|}{$\begin{array}{l}\text { Median } \\
\text { age at } \\
\text { diagnosis } \\
\text { of the } \\
\text { SMs, yrs }\end{array}$} & \multicolumn{2}{|c|}{$\begin{array}{l}\text { Median } \\
\text { follow-up } \\
\text { time since } \\
\text { the diag- } \\
\text { nosis of } \\
\text { SMs, } \\
\text { months } \\
\end{array}$} & \multicolumn{2}{|c|}{$\begin{array}{l}\text { Median } \\
\text { latency } \\
\text { time, } \\
\text { months }\end{array}$} \\
\hline & $+\mathrm{RAI}$ & -RAI & $+\mathrm{RAI}$ & -RAI & $+\mathrm{RAI}$ & -RAI & $+\mathrm{RAI}$ & -RAI & $+\mathrm{RAI}$ & -RAI & $+\mathrm{RAI}$ & -RAI & $+\mathrm{RAI}$ & -RAI \\
\hline $\begin{array}{l}\text { All cancer } \\
\text { combined }\end{array}$ & 2289 & 2339 & $68.7 \%$ & $72.6 \%$ & $\begin{array}{l}83 \% / 5 \% / \\
11 \%\end{array}$ & $\begin{array}{l}85 \% / 8 \% \\
10 \%\end{array}$ & $\begin{array}{l}50 \% / 18 \% \\
/ 17 \%\end{array}$ & $\begin{array}{l}50 \% / 21 \% \\
/ 16 \%\end{array}$ & 62 & 64 & 28 & 26 & 70 & 70 \\
\hline $\begin{array}{l}\text { Oral Cavity and } \\
\text { Pharynx }\end{array}$ & 56 & 51 & $64.3 \%$ & $64.7 \%$ & $\begin{array}{l}79 \% / 5 \% \\
/ 16 \%\end{array}$ & $\begin{array}{l}78 \% / 12 \% / \\
10 \%\end{array}$ & $48 \% / 11 \% / 7 \%$ & $39 \% / 12 \% / 8 \%$ & 58 & 59 & 22 & 24 & 68 & 73 \\
\hline Digestive System & 319 & 356 & $69.0 \%$ & $72.5 \%$ & $\begin{array}{l}78 \% / 8 \% \\
/ 14 \%\end{array}$ & $\begin{array}{l}81 \% / 10 \% / \\
10 \%\end{array}$ & $36 \% / 28 \% / 24 \%$ & $34 \% / 32 \% / 4 \%$ & 64 & 65 & 19 & 14 & 73 & 68 \\
\hline Respiratory System & 247 & 254 & $68.8 \%$ & $72.4 \%$ & $\begin{array}{l}82 \% / 5 \% \\
/ 12 \%\end{array}$ & $83 \% / 9 \% / 8 \%$ & $24 \% / 17 \% / 52 \%$ & $24 \% / 24 \% / 48 \%$ & 68 & 66 & 14 & 10 & 68 & 66 \\
\hline Skin & 138 & 137 & $63.0 \%$ & $67.2 \%$ & $96 \% / 1 \% / 4 \%$ & $96 \% / 1 \% / 2 \%$ & $76 \% / 9 \% / 3 \%$ & $78 \% / 11 \% / 1 \%$ & 56 & 64 & 35 & 31 & 65 & 68 \\
\hline Breast & 547 & 574 & $99.5 \%$ & $99.8 \%$ & $\begin{array}{l}80 \% / 5 \% \\
/ 15 \%\end{array}$ & $82 \% / 10 \% / 8 \%$ & $65 \% / 30 \% / 4 \%$ & $66 \% / 30 \% / 3 \%$ & 58 & 61 & 35 & 34 & 73 & 74 \\
\hline $\begin{array}{l}\text { Female Genital } \\
\text { System }\end{array}$ & 179 & 206 & $100.0 \%$ & $100.0 \%$ & $\begin{array}{l}83 \% / 7 \% \\
/ 10 \%\end{array}$ & $\begin{array}{l}82 \% / 5 \% \\
/ 12 \%\end{array}$ & $61 \% / 16 \% / 16 \%$ & $51 \% / 23 \% / 21 \%$ & 60 & 62 & 29 & 26 & 66 & 67 \\
\hline Male Genital System & 237 & 233 & $0.0 \%$ & $0.0 \%$ & $84 \% / 7 \% / 9 \%$ & $88 \% / 9 \% / 3 \%$ & $79 \% / 14 \% / 3 \%$ & $82 \% / 12 \% / 2 \%$ & 65 & 66 & 38 & 50 & 70 & 69 \\
\hline Urinary System & 194 & 191 & $43.3 \%$ & $57.6 \%$ & $89 \% / 3 \% / 8 \%$ & $90 \% / 5 \% / 6 \%$ & $55 \% / 12 \% / 10 \%$ & $56 \% / 9 \% / 8 \%$ & 64 & 67 & 30 & 31 & 71 & 78 \\
\hline Nervous System & 30 & 36 & $80.0 \%$ & $69.4 \%$ & $87 \% / 7 \% / 7 \%$ & $94 \% / 3 \% / 0 \%$ & $73 \% / 20 \% / 3 \%$ & $86 \% / 8 \% / 0 \%$ & 57 & 60 & 15 & 12 & 55 & 60 \\
\hline Hematologic System & 261 & 215 & $65.1 \%$ & $65.6 \%$ & $\begin{array}{l}84 \% / 4 \% \\
/ 11 \%\end{array}$ & $87 \% / 7 \% / 4 \%$ & NA & NA & 63 & 66 & 27 & 23 & 65 & 73 \\
\hline
\end{tabular}

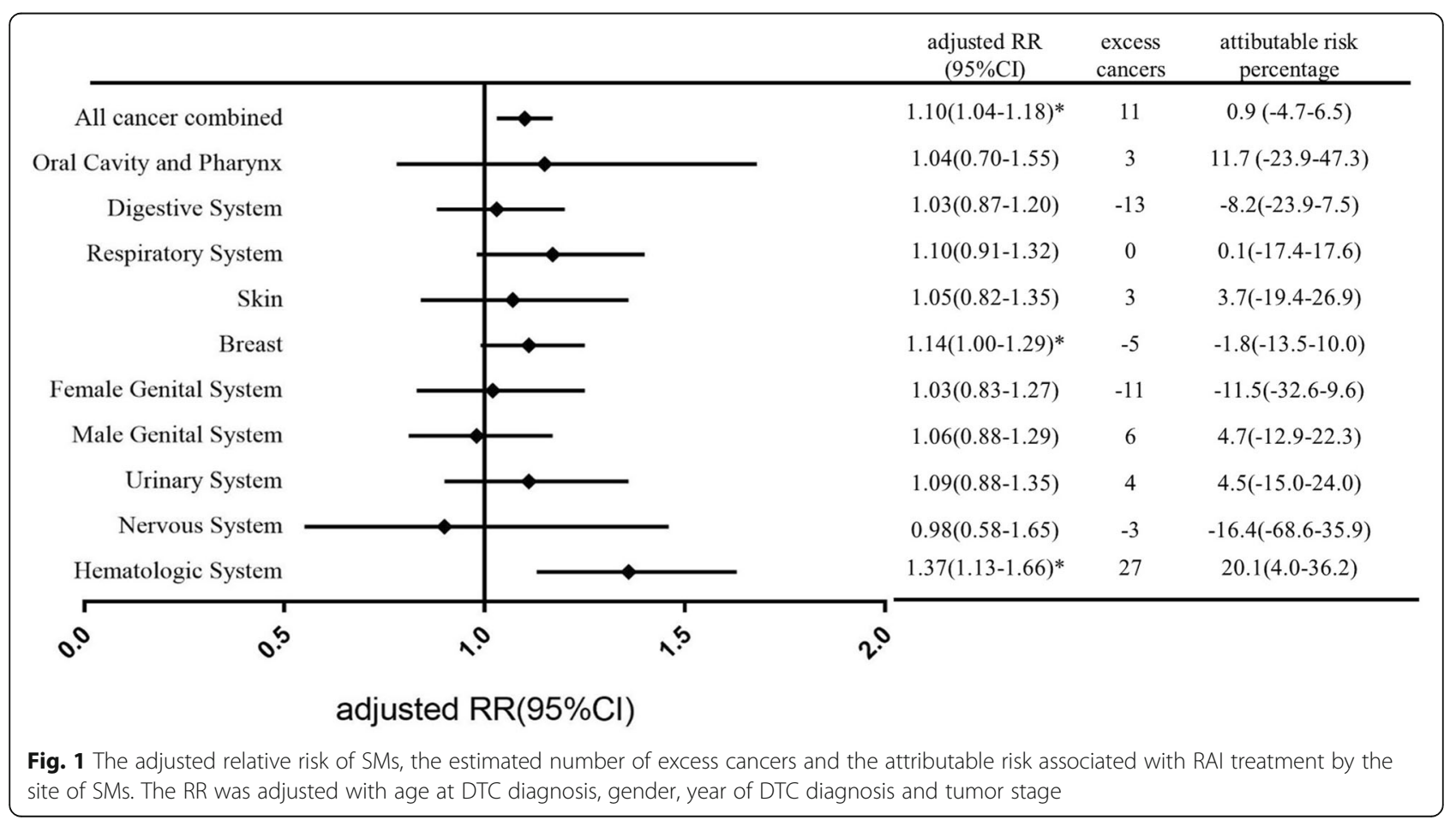


Table 3 Relative risk of all SMs or hematologic SMs for RAI therapy by different stratification

\begin{tabular}{|c|c|c|c|c|}
\hline \multirow[b]{2}{*}{ Stratified by diagnosed age } & \multicolumn{2}{|c|}{ All cancer combined } & \multicolumn{2}{|c|}{ Hematologic SMs } \\
\hline & $\mathrm{RR}(95 \% \mathrm{Cl})$ & $P$ value & $\mathrm{RR}(95 \% \mathrm{Cl})$ & $P$ value \\
\hline$<45$ yrs & $1.05(0.92-1.21)$ & 0.454 & $2.17(1.08-4.38)$ & 0.035 \\
\hline $45-59$ yrs & 1.08(0.99-1.19) & 0.094 & $1.50(1.06-2.10)$ & 0.02 \\
\hline $60-74$ yrs & $1.17(1.05-1.30)$ & 0.004 & $1.70(1.29-2.25)$ & 0.000 \\
\hline$>=75 \mathrm{yrs}$ & 1.18(0.96-1.46) & 0.123 & 1.04(0.69-1.58) & 0.832 \\
\hline \multicolumn{5}{|l|}{ Stratified by gender } \\
\hline female & $1.01(0.94-1.08)$ & 0.816 & $1.31(1.05-1.64)$ & 0.016 \\
\hline male & $0.94(0.85-1.05)$ & 0.303 & $1.04(0.76-1.41)$ & 0.814 \\
\hline \multicolumn{5}{|l|}{ Stratified by latency time } \\
\hline$<5 \mathrm{yrs}$ & $1.11(1.01-1.22)$ & 0.025 & $1.83(1.14-2.94)$ & 0.012 \\
\hline $5-10 y r s$ & 1.03(0.94-1.13) & 0.536 & $1.13(0.85-1.50)$ & 0.413 \\
\hline $10-15$ yrs & $0.88(0.76-1.02)$ & 0.086 & $1.19(0.88-1.62)$ & 0.266 \\
\hline$>=15 \mathrm{yrs}$ & $0.75(0.43-1.33)$ & 0.325 & $0.97(0.56-1.67)$ & 0.898 \\
\hline
\end{tabular}

compared to those did not receive $\mathrm{RAI}(\mathrm{RR}=1.31,95 \% \mathrm{CI}$ : 1.05-1.64, $P=0.016$ ). The RRs of SMs relative to RAI treatment were significantly elevated in the first 5 years after DTC diagnosis (all cancer combined: $R R=1.11$, 95\%CI:1.01-1.22, $P=0.025$; hematologic cancers: $\mathrm{RR}=$ 1.83 , 95\%CI:1.14-2.94, $P=0.012$ ) and gradually decreased with increasing time since DTC diagnosis (Table 3).

\section{Comparison of SMs between RAI-treated and non RAI treated DTC survivors}

Although RAI+ patients tend to be diagnosed with DTC of higher tumor stage, the features of SMs and the outcome of patients are overally comparable in RAI+ and RAI- patients (Tables 2 and 4). The descriptive characteristics of SMs between two groups of patients are presented in Table 2. DTC patients receiving RAI treatment tend to have higher tumor stage (Table 1), but the proportion of patients developed SMs are comparable in
RAI+ and RAI- group (Table 2), indicating tumor stage has little effect on the relative risk of SMs development associated to RAI treatment. There are a few exceptions: a longer follow-up time were seen in RAI+ patients developing SMs of skin and in RAI- treated patients developing SMs of male genital system; and a lower mortality in RAI treated patients developing SMs of digestive system. DTC survivors treated with RAI tend to have a lower overall mortality and disease specific mortality (death caused by SPM), although no statistically significance (Table 4).

\section{Discussion}

As the good prognosis of DTC, developing a SM is probably the greatest concern in DTC survivors [20]. Indeed, SM has been reported as a major cause of mortality and serious morbidity in DTC survivors. Compared to the general population, DTC survivors have a $10-30 \%$

Table 4 The mortality of DTC survivors developing SMs by different sites

\begin{tabular}{|c|c|c|c|c|c|c|}
\hline & \multicolumn{3}{|c|}{ overall mortality } & \multicolumn{3}{|c|}{ disease specific mortality } \\
\hline & with RAI & no RAI & $P$ value & with RAI & no RAI & $P$ value \\
\hline All cancer combined & $25.5 \%$ & $28.0 \%$ & 0.001 & $16.4 \%$ & $18.3 \%$ & 0.081 \\
\hline Oral Cavity and Pharynx & $26.8 \%$ & $23.5 \%$ & 0.008 & $7.1 \%$ & $3.9 \%$ & 0.681 \\
\hline Digestive System & $39.5 \%$ & $47.2 \%$ & 0.052 & $32.3 \%$ & $36.8 \%$ & 0.225 \\
\hline Respiratory System & $62.3 \%$ & $61.0 \%$ & 0.783 & $47.8 \%$ & $49.2 \%$ & 0.789 \\
\hline Skin & $12.3 \%$ & $11.7 \%$ & 1.000 & $5.1 \%$ & $2.9 \%$ & 0.54 \\
\hline Breast & $9.9 \%$ & $11.0 \%$ & 0.559 & $4.8 \%$ & $5.9 \%$ & 0.427 \\
\hline Female Genital System & $20.1 \%$ & $22.8 \%$ & 0.537 & $14.5 \%$ & $19.4 \%$ & 0.224 \\
\hline Male Genital System & $8.4 \%$ & $9.0 \%$ & 0.871 & $3.4 \%$ & $3.4 \%$ & 1.000 \\
\hline Urinary System & $17.5 \%$ & $19.9 \%$ & 0.602 & $10.3 \%$ & $8.9 \%$ & 0.73 \\
\hline Nervous System & $63.3 \%$ & $66.7 \%$ & 0.801 & $60.0 \%$ & $63.9 \%$ & 0.802 \\
\hline Hematopoietic System & $25.7 \%$ & $29.3 \%$ & 0.409 & $17.2 \%$ & $20.9 \%$ & 0.347 \\
\hline
\end{tabular}


higher risk of developing a SM [5-8], due to the genetic predisposition, environmental factors, lifestyle, and the cancer treatment they received. RAI is commonly used in DTC treatment for three purposes: 1) RAI remnant ablation to facilitate detection of recurrent disease in the surveillance with serum thyroglobulin; 2) RAI adjuvant therapy to eliminate suspected residual disease; 3) RAI therapy to treat persistent disease $[9,21]$. Many evidences have shown that RAI treatment can decrease the metastasis and improve the survival of DTC patients [22-24]. For low- and intermediate-risk patients, RAI treatment is gradually questioned in the recent few years, as some studies indicated these patients have relative good prognosis, but will risk themselves to develop a SM if receiving RAI treatment $[6-8,16,25]$. However, extensive oppositions existed [26-29]. Considerable arguments about the balance between benefits and harms, as well as the quality of patient care, were generated and widely spread in physicians, especially in the nuclear medicine community [26-29].

The risk of SMs development associated with RAI in DTC survivors have been investigated and debated for decades $[5-8,16,30]$. Many studies presented their evaluations in a way may be interpreted by statisticians, but not the majority of clinical physicians, who will really read these statistics with the goal of weighting the pros and cons of RAI treatment in their patients. Therefore, in this study, we comprehensively analyzed the risk associated with RAI, also compared the clinical features of SMs as well as the mortality of RAI+ and RAI- treated patients. More specifically, we estimated the proportion of SMs risk directly associated with RAI, which for the first time quantitatively showed the absolute risk of RAI in inducing SMs. These data can be more easily and intuitively interpreted by physicians and patients. Our main findings include: 1) The adjusted RR associated with RAI was only significantly increased for SMs of hematologic systems and breast; 2) Only $0.9 \%$ of all cancer combined SMs are estimated to be attributed to RAI treatment; the proportion is relatively high in patients developing SMs in hematologic systems and oral cavity and pharynx system (20.1 and $11.7 \%$ respectively);3) The RRs of all cancer combined SMs associated with RAI generally increased with age at DTC diagnosis and decreased with the latency time; by contrast, the RRs of hematologic SMs peaked in patients with DTC diagnosed younger than 45 yrs., and then decreased with age at DTC diagnosis; 4) The clinical features and mortality are overally comparable between RAI+ and RAIpatients.

Many studies have claimed that RAI would associate with a risk of SM development as its carcinogenesis effect, but the real concern is how much the risk is and how the absolute number is. In this study, we estimated that the attributable risk of RAI treatment for all cancer combined SMs was only $0.9 \%$. Given the relative low incidence of SMs in DTC survivors (4.4\%) and this small attributable risk proportion of RAI treatment, the absolute number of SMs associated with RAI treatment in DTC survivors would be low. Hematologic system is the most susceptible system to develop SMs after RAI treatment, the adjusted RR is $1.37(95 \% \mathrm{CI}: 1.13-1.66, P=$ 0.001 ) and the attributable risk proportion of RAI treatment is around 20\%, which is the highest among all cancers. However, the incidence of hematologic SMs in all DTC survivors is only $0.46 \%$, indicating the absolute number would be low. In addition, there is no way to exclude the effect of hyperthyroidism on the hematologic SMs development. RAI treated patients usually are in iatrogenic subclinical hyperthyroidism, which has been reported as an independent risk factor for leukemia [27, 31]. Taken together with these factors, we think both physicians and patients should be rational about the risk associated with RAI in inducing hematologic SMs.

Although patients receiving RAI treatment tend to have higher stage of DTC tumor, the clinical features of SMs are comparable between $\mathrm{RAI}+$ and RAI- patients, indicating neither RAI treatment nor the intrinsic biological aggressiveness of DTC tumor would affect the clinical feature of SMs. Consistent with the clinical features, SM specific mortalities are also comparable in two groups of patients. However, the overall mortalities tend to be lower in RAI treated patients, with statistical significance for all cancer combined SMs. Surveillance bias cannot be ruled out for the lower mortality, as indolent malignancies are more likely to be discovered during the frequent surveillances in RAI+ patients and/or these patients are more likely to change their lifestyle due to their more advanced tumors. Other factors interacting with RAI may also contribute to the lower mortality.

The main limitation of the SEER data is lacking the amounts of administered activities of RAI, therefore, it is not possible to determine the dose-response effect of RAI in this study. Some studies with available information observed an increased leukemia risk associated with RAI, but only with a dosage higher than $100 \mathrm{mCi}$ or even $150 \mathrm{mCi}[16,25]$. This means only a small percentage of patients, who accept RAI activity that above the most commonly used dosage $(50-100 \mathrm{mCi})$, should be concern of this increased risk. However, in the other hand, patients receiving this high amount of dosage usually have advanced tumors in which RAI has shown survival advantage [9]. Therefore, it is critical to weight the benefits and harms of RAI treatment, and determine the dosage of RAI in each individual DTC survivors in clinical practice.

In summary, in this population based data analysis, we found only for SMs of hematologic and breast SMs, RAI 
treatment is associated with an increased RRs. For all cancer combined SMs, a low proportion is associated with RAI treatment. Only for hematologic SMs, RAI treatment accounts for a relative high attributable risk proportion. In consideration of the low incidence of SMs in all DTC survivors, the absolute number of SMs in DTC patients would be small, including hematologic SMs. Tumor features and the mortality of RAI+ and RAI- patients are comparable. Taken all these together, we think it is important to provide the most careful assessment of risks and benefits of RAI to each individual patient in clinical practice, but should not be panicked by the potential risk of SMs.

\section{Supplementary Information}

The online version contains supplementary material available at https://doi. org/10.1186/s12885-021-08292-8.

Additional file 1 Fig. S1. The spectrum of SMs in patients treated with and without RAI. The $x$ axis shows different cancer types by their sites while $y$ axis shows the percentage of different SMs among all cancer combined. Except for cancers of digestive and hematologic system, the spectrum of different SMs in the two groups (blue line: treated with RAl; red line: not treated with RAI) are overally similar. Table S1. The incidence of SMs in all DTC survivors and the proportion of each system of SMs by their sites. The second column (Incidence in all DTC survivors) shows the incidence of different SMs among all DTC survivors (104,026 patients in total), the third and fourth column shows the number (proportion in all SMs) of different SMs by their sites. Table S2. The crude relative risk of SMs associated with RAI treatment by the site of SMs.

\section{Acknowledgements}

We thank Xiaopei Shen (Fujian Medical University, China) for providing suggestions for statistics, and Chenglai Fu (Tianjin Medical University, China) for manuscript editing.

\section{Authors' contributions}

X.M. and X.Y. extracted and analyzed the data, prepared the Figs. X.M. and F.F. prepared the figures and Tables. W.C. and H.W. conducted the project and wrote the manuscript. All authors reviewed the manuscript. All authors read and approved the final manuscript.

\section{Funding}

This work is supported by the National Natural Science Fund (grant number 81974269, and 81901162).

\section{Availability of data and materials}

The datasets analyzed during the current study available from the corresponding author on reasonable request.

\section{Declarations}

Ethics approval and consent to participate

This article does not contain any studies with human participants or animals performed by any of the authors, thus there is no compliance with ethical standard.

\section{Consent for publication}

Written informed consent for publication was obtained from all authors.

\section{Competing interests}

The authors declare no competing interests.

\section{Author details}

${ }^{1}$ Xin Hua Hospital Affiliated to Shanghai Jiao Tong University School of Medicine, Shanghai, China. ${ }^{2}$ The Affiliated Yantai Yuhuangding Hospital of Qingdao University, Yantai, China.

Received: 29 December 2020 Accepted: 30 April 2021

Published online: 13 May 2021

\section{References}

1. Surveillance E, Results E: (SEER) Program (www.seer.cancer.gov) Research Data (1973-2014), National Cancer Institute, DCCPS, Surveillance Research Program, Surveillance Systems Branch, released April 2017, based on the November 2016 submission.

2. Veiga LH, Neta G, Aschebrook-Kilfoy B, et al. Thyroid cancer incidence patterns in Sao Paulo, Brazil, and the U.S. SEER program, 1997-2008. Thyroid. 2013;23(6):748-57. https://doi.org/10.1089/thy.2012.0532.

3. Gilliland FD, Hunt WC, Morris DM, Key CR. Prognostic factors for thyroid carcinoma. A population-based study of 15,698 cases from the Surveillance, epidemiology and end Results (SEER) program 1973-1991. Cancer. 1997; 79(3):564-73. https://doi.org/10.1002/(SICI)1097-0142(19970201)79:3<564::A ID-CNCR2O>3.0.CO;2-0.

4. Lau BJ, Goldfarb M. Age at primary malignancy determines survival in adolescent and young adults that develop a secondary thyroid Cancer. J Adolesc Young Adult Oncol. 2016;5(2):201-8. https://doi.org/10.1089/jayao.2015.0052.

5. Subramanian S, Goldstein DP, Parlea L, Thabane L, Ezzat S, Ibrahim-Zada I, et al. Second primary malignancy risk in thyroid cancer survivors: a systematic review and meta-analysis. Thyroid. 2007;17(12):1277-88. https:// doi.org/10.1089/thy.2007.0171.

6. Molenaar RJ, Sidana S, Radivoyevitch T, Advani AS, Gerds AT, Carraway HE, et al. Risk of hematologic malignancies after radioiodine treatment of welldifferentiated thyroid Cancer. J Clin Oncol. 2018;36(18):1831-9. https://doi. org/10.1200/JCO.2017.75.0232.

7. Rubino C, de Vathaire F, Dottorini ME, Hall P, Schvartz C, Couette JE, et al. Second primary malignancies in thyroid cancer patients. Br J Cancer. 2003; 89(9):1638-44. https://doi.org/10.1038/sj.bjc.6601319.

8. Brown AP, Chen J, Hitchcock YJ, Szabo A, Shrieve DC, Tward JD. The risk of second primary malignancies up to three decades after the treatment of differentiated thyroid cancer. J Clin Endocrinol Metab. 2008;93(2):504-15. https://doi.org/10.1210/jc.2007-1154.

9. Haugen BR, Alexander EK, Bible KC, Doherty GM, Mandel SJ, Nikiforov YE, et al. 2015 American Thyroid Association management guidelines for adult patients with thyroid nodules and differentiated thyroid Cancer: the American Thyroid Association guidelines task force on thyroid nodules and differentiated thyroid Cancer. Thyroid. 2016;26(1):1-133. https://doi.org/10.1 089/thy.2015.0020

10. Jonklaas J, Sarlis NJ, Litofsky D, Ain KB, Bigos ST, Brierley JD, et al. Outcomes of patients with differentiated thyroid carcinoma following initial therapy. Thyroid. 2006;16(12):1229-42. https://doi.org/10.1089/thy.2006.16.1229.

11. Grani G, Zatelli MC, Alfò M, Montesano T, Torlontano M, Morelli S, et al. Real-world performance of the American Thyroid Association risk estimates in predicting 1-year differentiated thyroid Cancer outcomes: a prospective multicenter study of 2000 patients. Thyroid. 2021;31(2):264-71. https://doi. org/10.1089/thy.2020.0272.

12. Park KW, Wu JX, Du L, et al. Decreasing use of radioactive iodine for low-risk thyroid Cancer in California, 1999 to 2015. J Clin Endocrinol Metab. 2018; 103(3):1095-101. https://doi.org/10.1210/jc.2017-02269.

13. Jacobs D, Breen CT, Pucar D, Holt EH, Judson BL, Mehra S. Changes in population-level and institutional-level prescribing habits of radioiodine therapy for papillary thyroid Cancer. Thyroid. 2021;31(2):272-9. https://doi. org/10.1089/thy.2020.0237.

14. Yu CY, Saeed O, Goldberg AS, Faroog S, Fazelzad R, Goldstein DP, et al. A systematic review and meta-analysis of subsequent malignant neoplasm risk after radioactive iodine treatment of thyroid Cancer. Thyroid. 2018;28(12): 1662-73. https://doi.org/10.1089/thy.2018.0244.

15. Sawka AM, Thabane L, Parlea L, Ibrahim-Zada I, Tsang RW, Brierley JD, et al. Second primary malignancy risk after radioactive iodine treatment for thyroid cancer: a systematic review and meta-analysis. Thyroid. 2009;19(5): 451-7. https://doi.org/10.1089/thy.2008.0392.

16. Teng CJ, Hu YW, Chen SC, et al. Use of radioactive iodine for thyroid cancer and risk of second primary malignancy: a nationwide population-based study. J Natl Cancer Inst. 2015;108(2):djv314. 
17. de GA B, Curtis RE, Kry SF, et al. Proportion of second cancers attributable to radiotherapy treatment in adults: a cohort study in the US SEER cancer registries. Lancet Oncol. 2011;12(4):353-60.

18. de GA B, Curtis RE, Gilbert E, et al. Second solid cancers after radiotherapy for breast cancer in SEER cancer registries. Br J Cancer. 2010;102(1):220-6.

19. Cheng W, Shen XP, Xing M. Decreased breast cancer-specific mortality risk in patients with a history of thyroid cancer. PLoS One. 2019;14(10):e0221093. https://doi.org/10.1371/journal.pone.0221093.

20. Liou MJ, Tsang NM, Hsueh C, Chao TC, Lin JD. Therapeutic outcome of second primary malignancies in patients with well-differentiated thyroid Cancer. Int J Endocrinol. 2016;2016:9570171.

21. Tuttle RM, Ahuja S, Avram AM, Bernet VJ, Bourguet P, Daniels GH, et al. Controversies, consensus, and collaboration in the use of 1311 therapy in differentiated thyroid Cancer: a joint statement from the American Thyroid Association, the European Association of Nuclear Medicine, the Society of Nuclear Medicine and Molecular Imaging, and the European thyroid association. Thyroid. 2019;29(4):461-70. https://doi.org/10.1089/thy.2018. 0597.

22. Haymart MR, Banerjee M, Stewart AK, Koenig RJ, Birkmeyer JD, Griggs JJ. Use of radioactive iodine for thyroid cancer. JAMA. 2011;306(7):721-8. https://doi.org/10.1001/jama.2011.1139.

23. Ruel E, Thomas S, Dinan M, Perkins JM, Roman SA, Sosa JA. Adjuvant radioactive iodine therapy is associated with improved survival for patients with intermediate-risk papillary thyroid cancer. J Clin Endocrinol Metab. 2015;100(4):1529-36. https://doi.org/10.1210/jc.2014-4332.

24. Kammori M, Fukumori T, Sugishita Y, Hoshi M, Shimizu K, Yamada T. Radioactive iodine (RAl) therapy for distantly metastatic differentiated thyroid cancer (DTC) in juvenile versus adult patients. Endocr J. 2015;62(12): 1067-75. https://doi.org/10.1507/endocrj.EJ15-0451.

25. Seo GH, Cho YY, Chung JH, Kim SW. Increased risk of leukemia after radioactive iodine therapy in patients with thyroid Cancer: a Nationwide, Population-Based Study in Korea. Thyroid. 2015;25(8):927-34. https://doi. org/10.1089/thy.2014.0557.

26. Tulchinsky M, Baum RP, Bennet KG, Freeman LM, Jong I, Kairemo K, et al. Well-founded recommendations for radioactive iodine treatment of differentiated thyroid Cancer require balanced study of benefits and harms. J Clin Oncol. 2018:36(18):1887-8. https://doi.org/10.1200/JCO.2018.78.5972.

27. Greenspan BS. Radioiodine treatment of well-differentiated thyroid Cancer: balancing risks and benefits. J Clin Oncol. 2018;36(18):1785-7. https://doi. org/10.1200/JCO.2018.78.6384.

28. Metter D, Phillips WT, Walker RC, Blumhardt R. To use or not to use 1311 in thyroid Cancer. Clin Nucl Med. 2018;43(9):670-1. https://doi.org/10.1097/ RLU.0000000000002190.

29. Verburg FA, Giovanella L, lakovou I, Konijnenberg MW, Langsteger W, Lassmann $M$, et al. I-131 as adjuvant treatment for differentiated thyroid carcinoma may cause an increase in the incidence of secondary haematological malignancies: an "inconvenient" truth? Eur J Nucl Med Mol Imaging. 2018;45(13):2247-9. https://doi.org/10.1007/s00259-018-4184-z.

30. McLeod DS, Sawka AM, Cooper DS. Controversies in primary treatment of low-risk papillary thyroid cancer. Lancet. 2013;381(9871):1046-57. https://doi. org/10.1016/S0140-6736(12)62205-3.

31. Saenger EL, Thoma GE, Tompkins EA. Incidence of leukemia following treatment of hyperthyroidism. Preliminary report of the cooperative thyrotoxicosis therapy follow-up study. JAMA. 1968;205(12):855-62. https:// doi.org/10.1001/jama.1968.03140380059014.

\section{Publisher's Note}

Springer Nature remains neutral with regard to jurisdictional claims in published maps and institutional affiliations.

Ready to submit your research? Choose BMC and benefit from:
- fast, convenient online submission
- thorough peer review by experienced researchers in your field
- rapid publication on acceptance
- support for research data, including large and complex data types
- gold Open Access which fosters wider collaboration and increased citations
- maximum visibility for your research: over 100M website views per year
At BMC, research is always in progress.
Learn more biomedcentral.com/submissions

